Estudios Constitucionales, Año 11, No 1, 2013, pp. 621 - 632.

ISSN 0718-0195

Centro de Estudios Constitucionales de Chile Universidad de Talca

"Comentario jurisprudencial: la consulta a los pueblos indígenas en la sentencia del Tribunal

Constitucional sobre Ley de Pesca, roles Nos. 2387-12 y 2388-12CPT, acumulados"

Liliana Galdámez Zelada

\title{
COMENTARIO JURISPRUDENCIAL: LA CONSULTA A LOS PUEBLOS INDÍGENAS EN LA SENTENCIA DEL TRIBUNAL CONSTITUCIONAL SOBRE LEY DE PESCA ROLES Nos. 2387-12-CPT Y 2388-12-CPT, ACUMULADOS
}

\author{
Liliana GaLdÁmeZ ZeladA* \\ Profesora de Derecho Constitucional Universidad de Talca
}

La sentencia sobre Ley de Pesca y Acuicultura rompe con los criterios sentados por el propio Tribunal Constitucional en relación a las normas autoejecutables de los tratados internacionales sobre derechos humanos. Decimos que rompe y queremos resaltarlo, porque era la oportunidad para que siguiendo su doctrina, reconociera la fuerza normativa de las normas autoejecutables contenidas en el Convenio 169, así declaradas por el propio Tribunal en su jurisprudencia anterior ${ }^{1}$.

Como ocurre con algunas materias que el TC analiza, estamos en presencia de un asunto de interés nacional ya que lo que está en juego es la constitucionalidad de artículos clave de la Ley No 18.892 que regula la pesca y desarrollo de la acuicultura en nuestro país ${ }^{2}$.

Considera el Tribunal que la "médula del cuestionamiento constitucional" a la modificación a la ley general de pesca, es que se omitió durante su tratamiento

\footnotetext{
* Doctora en Derecho por la Universidad de Valladolid, Licenciada en Ciencias Jurídicas y Sociales Universidad de Chile, abogada. Este trabajo se desarrolla en el marco del proyecto "Análisis de las sentencias del Tribunal Constitucional sobre utilización del Derecho Constitucional Extranjero y del Derecho Internacional de los Derechos Humanos y sus Implicancias para el Parámetro de Control de Constitucionalidad", patrocinado por el Fondo Nacional de Desarrollo Científico y Tecnológico, Fondecyt, del que soy co investigadora. lgadamez@utalca.cl

${ }^{1}$ Sentencia rol 309 del Tribunal de 4 de agosto de 2000.

2 El requerimiento fue presentado por 11 senadores por inconstitucionalidad de los arts.: 27 que se refiere a subasta de cuota global de captura que otorga licencias por vigencia de 20 años; art. $3^{\circ}$ sobre fijación de cuotas anuales de captura por especie en un área determinada o cuotas globales de captura por hasta 3 años; la contenida en el art. 48 del artículo 1 de proyecto sobre registro independiente del de la $\mathrm{V}$ Región para el Registro artesanal de Isla de Pascua. Más adelante, en el proceso Rol No 2388 un requerimiento similar formuló un grupo de diputados, que consideran que las normas afectan a los pueblos originarios cuyo sistema de consulta está regulado en el Decreto Supremo No 124 de 2009 de Mideplan. En total 11 senadores y 45 diputados formularon dicho reclamo.
} 
en sede legislativa el cumplimiento de normas (tanto autoejecutables como programáticas) contenidas en el Convenio 169 de la Organización Internacional del Trabajo sobre Pueblos Indígenas y Tribales en Países Independientes que, además, los requirentes consideran de rango constitucional ${ }^{3}$.

Sobre las cuestiones debatidas, el Tribunal Constitucional desecha por no cumplir con las exigencias minimas para configurar una verdadera cuestión de constitucionalidad, precisa y concreta, los cuestionamientos que se formulan respecto de las normas del proyecto de ley contenidas en el $\left.N^{\circ} 20\right)$ del artículo 10; en la letra c) del $\left.N^{\circ} 3\right)$ del artículo $1^{\circ}$, y en el $N^{o} 48$ del mismo artículo. Respecto a la petición de declarar la nulidad de derecho público, también se desecha de plano por improcedente. Es en relación con el vicio alegado en el proceso de formación de la ley por omisión del deber de consulta que el tribunal se pronunciará en extenso.

Veremos en los apartados siguientes a qué conclusiones llega el tribunal, sobre la base de qué fundamentos y revisaremos cuál ha sido la doctrina sostenida por el TC en relación a la consulta. Adelantamos desde ya nuestro juicio crítico teniendo a la vista la ruptura de la secuencia lógica y esperable según criterios que el Tribunal había introducido en las sentencias roles 309 y 1050.

La sentencia, además de su interés por la materia que analiza, es destacable ya que el Tribunal retoma su anterior doctrina sobre el valor de los tratados internacionales sobre derechos humanos y con ello limita interpretaciones de mayor apertura al Derecho Internacional en materia de derechos humanos.

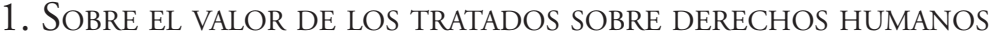

Dado que uno de los argumentos de los requirentes es el valor o jerarquía constitucional de los tratados internacionales ratificados y vigentes, el tribunal analiza las fórmulas existentes en el derecho comparado para concluir y reiterar que en nuestro ordenamiento, a partir de los arts. 5º, 32 No 17 y 54 No 1 de la $\mathrm{CPR}$, no se contienen normas que de manera explícita reconozcan el rango normativo de los tratados internacionales, ni aun cuando ellos se refieran a derechos esenciales que emanan de la naturaleza humana. Concluye, que de su contexto

\footnotetext{
${ }^{3}$ En resumen, considera el Tribunal que estamos en presencia de una cuestión constitucional múltiple y referida a: cuestionamiento de tres de sus normas por atentatorias a ciertas garantías constitucionales; un cuestionamiento accesorio que consiste en que el proyecto sería nulo de derecho público por infracción de los arts. $6^{\circ}$ y $7^{\circ}$ de la CPR al no haberse consultado a los pueblos indígenas, conforme al Convenio 169 de la OIT; y, por un vicio en la formación de la ley al no haberse cumplido con la norma autoejecutable prevista en el art. 6 del convenio y otras normas programáticas contenidas en dicho convenio, teniendo el tratado rango constitucional conforme al inciso segundo del art. $5^{\circ}$ de la Constitución.
} 
se puede concluir que los tratados internacionales tienen rango inferior a la Constitución y no superior ni igual a la ella. Dicho criterio, como es sabido, fue definido en la sentencia Rol No 346 sobre Estatuto de Roma que creó la Corte Penal Internacional.

En su reflexión sobre el sentido y alcance del inciso segundo del art. $5^{\circ}$, el TC señala, "que subraya y resalta, especialmente, el deber de todos los órganos del Estado de respetar y promover los derechos esenciales que emanan de la naturaleza humana garantizados por la Constitución, así como por los tratados internacionales ratificados por Chile y que se encuentren vigentes, como ocurre con el mencionado Convenio 169" 4 . Agrega que este deber corresponde a todos los órganos del Estado, y que incluso si la norma no existiese, la Convención de Viena reconoce el pacta sun servanda que obliga a su cumplimiento. En definitiva, considera el tribunal, el art. $5^{\circ}$ inciso segundo no hace más que reforzar esta obligación en materia de derechos humanos.

¿Cuáles son, en nuestra opinión, los problemas que plantea la posición del Tribunal Constitucional? Cuando en 2002 el Tribunal retomó el criterio sostenido en 1987 en la sentencia Rol No 46. No se habían dictado las sentencias donde se desarrolla la doctrina de los derechos esenciales que emanan de la naturaleza humana. Según esta doctrina dichos derechos comprenden tanto los derechos garantizados en la Constitución como los contenidos en tratados internacionales sobre derechos humanos. Esta tesis dio a su vez lugar al reconocimiento de la existencia de derechos implícitos, precisamente por corresponder a dicha categoría, estar vinculados a la dignidad del ser humano y estar contenidos en tratados internacionales ratificados y vigentes.

Asimismo, el derecho a la consulta ha sido ya examinado por el Tribunal en al menos tres ocasiones ( $r o l \mathrm{No}^{\circ}$. 309, 1050 y a propósito del Convenio UPOV rol 1988-11), por tanto, existen nuevos criterios en esta materia y que podemos resumir como a) reconocimiento del carácter de norma autoejecutable y orgánico constitucional a la consulta en dos casos; b) definición del sentido y alcance de la consulta.

En cuanto al primer asunto, más allá de la jerarquía de los tratados, el tribunal ha mostrado apertura (aunque pendular) al reconocimiento de nuevos derechos esenciales que emanan de la naturaleza humana contenidos en tratados ratificados y vigentes. No estamos en este punto frente a un problema de jerarquía normativa; el problema consiste en definir cuáles son las fuentes de los derechos fundamenta-

${ }^{4}$ Considerando Duodécimo. 
les en nuestro ordenamiento. Merece la pena destacar en este sentido lo señalado por el tribunal en la Sentencia Rol No 1340, "Asimismo, que aun cuando la Constitución chilena no reconozca, en su texto, el derecho a la identidad, ello no puede constituir un obstáculo para que el juez constitucional le brinde adecuada protección, precisamente por su estrecha vinculación con la dignidad humana y porque se encuentra protegido expresamente en diversos tratados internacionales ratificados por Chile y vigentes en nuestro país (Sentencia Rol No 834, considerando $\left.22^{\circ}\right)$... Las consideraciones que preceden justifican, precisamente, incluir el derecho a la identidad personal entre aquellos derechos esenciales a la naturaleza humana a que alude el artículo $5^{\circ}$, inciso segundo, de la Constitución, y que se erigen como límite de la soberanía, debiendo los órganos del Estado respetarlos y promoverlos, ya sea que estén asegurados en la propia Carta Fundamental o en tratados internacionales ratificados por Chile y que se encuentren vigentes".

La ubicación de los tratados por debajo de la Constitución no responde a la interrogante sobre los derechos que contienen dichos tratados, cuando son esenciales y emanan de la naturaleza humana. En efecto, si en 1987 la tesis del tribunal era coherente con su propia jurisprudencia, no ocurre lo mismo en 2013 cuando se han dictado ya un conjunto de sentencias que desarrollan la noción derechos esenciales que emanan de la naturaleza humana como una categoría que supone apertura constitucional en el catálogo de derechos.

Desde la perspectiva de los derechos implícitos, pudo definirse si el derecho a la consulta de los pueblos indígenas corresponde a esta categoría. Si estuviéramos en presencia de un derecho esencial, el incumplimiento del trámite de consulta previa durante la tramitación de la Ley de Pesca derivaría en una omisión en el proceso de formación de la ley que sólo podrían enmendarse previo cumplimiento del trámite de consulta y que daría lugar a una vulneración de la Constitución por defectos de fondo, en este caso por vulneración de derechos.

Pero, incluso, si nos situamos en el escenario donde la consulta no es un derecho esencial que emana de la naturaleza humana, de igual manera estaríamos ante un problema. En efecto, en su doctrina anterior el tribunal había declarado que en dos hipótesis el derecho a la consulta es una norma autoejecutable que incide en la tramitación de la ley. En este caso, el problema sería definir qué consecuencias derivan de esta omisión.

En cuanto a la doctrina sobre normas autoejecutables, el TC señaló que el Convenio 169 no tenía poder para reformar la Constitución, aunque sí modificaba la Ley Orgánica del Congreso Nacional. Desde esta perspectiva, la omisión del deber de consulta incidiría en un defecto en la tramitación de la ley que el Tribu- 
nal no podría controlar dado que no estamos ante una norma de la Constitución sino frente a una norma que desarrolla la Constitución. Conforme a esta tesis, la ausencia de cumplimiento del trámite de consulta, en cambio, sí podría llevar al juez del fondo a declarar el incumplimiento del trámite y con ello a declarar la nulidad. Como sea, estamos ante situaciones de gran complejidad cualquiera sea el camino de análisis que sigamos en relación a la omisión del deber de consulta.

En cualquier caso, para comprender este caso, habría sido pertinente que existiera un pronunciamiento del tribunal en relación a la procedencia -o no- de la consulta a los pueblos indígenas, cosa que el tribunal no hace.

\section{LA DOCTRINA SOBRE NORMAS AUTOEJECUTABLES SOSTENIDA EN LAS SENTENCIAS ROLES Nos. 309 y 1050}

Los primeros pronunciamientos en esta materia se produjeron en el marco del examen de constitucionalidad del Convenio 169 (rol No 309) y de la Convención sobre desaparición forzada de personas (rol No 383). En ambas sentencias se define qué entiende el TC por normas autoejecutables.

Para resumir los planteamientos del tribunal, podemos señalar que lo que distingue una norma autoejecutable de una que no lo es, es que la primera posee la aptitud y capacidad necesaria para ingresar al ordenamiento interno, como dice el tribunal, son normas autosuficientes y pueden aplicarse directamente. Por el contrario, una norma no autoejecutable, ha dicho el tribunal, es aquella que impone al Estado la obligación de dictar normas para hacer efectivo su cumplimiento. Sobre las primeras, el tribunal podrá pronunciarse en cuanto conozca sus contenidos, sobre las segundas sólo podrá opinar cuando la normativa complementaria se haya dictado, a menos que resulte evidente desde el momento en que conoce del tratado, que esta norma no es compatible con el ordenamiento interno.

Sobre normas autoejecutables y no autoejecutables el TC ha dicho:

"Las primeras, son las que tienen el contenido y precisión necesarias que las habilita para ser aplicadas sin otro trámite como fuente del derecho interno. En otros términos, son autosuficientes, y entran a la legislación nacional cuando el tratado que las contiene se incorpora al derecho vigente.

Las segundas, son aquellas que requieren para su entrada en vigencia de la dictación de leyes, reglamentos o decretos que las implementen y, en tal evento, las haga aplicables como fuente del derecho interno. En otras palabras, imponen la obligación al Estado, para que en uso de sus potestades públicas, sancione la normativa necesaria para que por esa vía les dé vigencia efectiva... 
Esta precisión resulta determinante para pronunciarse sobre la inconstitucionalidad de los preceptos del tratado, toda vez que aquellos cuyas normas o algunas de ellas requieran, para tener fuerza interna, de una actividad legislativa o administrativa posterior, no pueden, por esa razón, entrar en contradicción desde pronto con el ordenamiento constitucional ya que no son normas vigentes ni tampoco lo serán cuando el Presidente de la República ratifique el tratado si es que es aprobado por el Congreso y el Ejecutivo decide así hacerlo. Si los preceptos que se deben dictar para implementarlo, llegaren a contener disposiciones contrarias a la Constitución, ello será decidido en su oportunidad por los órganos de control de constitucionalidad que la propia Carta Fundamental establece.

Siendo así, en cada caso particular deberá previamente decidirse por este Tribunal si las disposiciones del tratado son o no autoejecutables y, por ende, si quedarán incorporadas, sin necesidad de otro acto de autoridad, al derecho interno. Sólo en el evento de que la norma sea autoejecutable, el Tribunal debe -en esta instancia jurisdiccional- pronunciarse sobre su constitucionalidad"5.

Este criterio fue posteriormente matizado en causa Rol No 383, de 5 de septiembre de 2003, donde el TC precisó: "Que, por otra parte, la distinción efectuada por la ya citada sentencia de este Tribunal de 4 de agosto de 2000, Rol No 309, entre normas autoejecutables y no autoejecutables, debe ser precisada para una comprensión cabal de la jurisprudencia de esta Magistratura, siendo ésta la oportunidad de hacerlo. Tal doctrina, desde luego y naturalmente, tiene una excepción importante. Ésta consiste en que si la norma no autoejecutable requiere de la aprobación por el Estado de Chile de preceptos que, conforme a la Constitución, conduzcan o puedan conducir a una inconstitucionalidad de fondo que afecte a la Convención, como podría ocurrir en la especie, no resulta aceptable ni razonable postergar una resolución sobre ella, habida consideración, en especial, de las disposiciones sobre cumplimiento de los tratados, con singular significación su artículo 27, contenidas en la Convención de Viena publicada en el Diario Oficial de 22 de junio de $1981 " 6$.

5 Rol No 309.

${ }^{6}$ Criterio ratificado en la sentencia Rol 1483-2009: "Que tal como tuvo oportunidad de señalarlo este Tribunal en sentencia de 4 de agosto de 2000, dictada en los autos Rol No 309, los tratados internacionales pueden contener dos tipos de cláusulas, denominadas por la doctrina 'self executing' y 'non self executing'.

Las primeras, son las que tienen el contenido y precisión necesarias que las habilita para ser aplicadas sin otro trámite como fuente del derecho interno. En otros términos, son autosuficientes, y entran a la legislación nacional cuando el tratado que las contiene se incorpora al derecho vigente". 
El TC consideró en la Sentencia Rol No 309 que el derecho a la consulta en dos hipótesis tiene el carácter autoejecutable:

a) Consulta en materia legislativa: "7o. Que, por su parte, el artículo 60, $\mathrm{N}^{\circ} 1^{\circ}$, letra a), del tratado en estudio -que lo requirentes denominan artículo $6^{\circ}$, inciso primero- establece 'Al aplicar las disposiciones del presente Convenio, los gobiernos deberán: a) consultar a los pueblos interesados, mediante procedimientos apropiados y en particular a través de sus instituciones representativas, cada vez que se prevean medidas legislativas o administrativas susceptibles de afectarles directamente'.

Esta norma, a juicio del Tribunal, tiene el carácter de autoejecutable o de aplicación directa, tanto por los términos perentorios en que se encuentra redactada como porque "la norma versa sobre una materia relativa a la tramitación de una ley que si bien, por cierto, no tiene la entidad o alcance de reformar los preceptos de los artículos 62 a 72 de la Carta Fundamental, sí está modificando las disposiciones de la Ley Orgánica Constitucional del Congreso Nacional, ya sea, por la vía de introducir una norma nueva que deberá observarse en la tramitación interna de la ley, ya sea, según algunos por estar convirtiendo en obligatorio para la comisiones legislativas, en cuanto a este punto se refiere, una atribución enteramente facultativa que las referidas comisiones pueden o no ejercer, según su leal saber y entender".

b) Consulta en materia de políticas públicas : "En efecto, el artículo 7o, № $1^{\circ}$, oración final, del tratado en estudio dispone: 'Además, dichos pueblos deberán participar en la formulación, aplicación y evaluación de los planes y programas de desarrollo nacional y regional susceptibles de afectarles directamente'. La simple lectura de este precepto es suficiente para estimar que estamos en presencia de una norma autoejecutable como se infiere con claridad de la forma imperativa en que se encuentra redactada al disponer que los pueblos 'deberán participar'. Está disposición en los términos en que está concebida, modifica parcialmente el

Las segundas, son aquellas que requieren para su entrada en vigencia de la dictación de leyes, reglamentos o decretos que las implementen y, en tal evento, las haga aplicables como fuente del derecho interno. En otras palabras, imponen la obligación al Estado, para que en uso de sus potestades públicas, sancione la normativa necesaria para que por esa vía les dé vigencia efectiva”.

7 "Artículo 7o. 1. Los pueblos interesados deberán tener el derecho de decidir sus propias prioridades en lo que atañe al proceso de desarrollo, en la medida en que éste afecte a sus vidas, creencias, instituciones y bienestar espiritual y a las tierras que ocupan o utilizan de alguna manera, y de controlar, en la medida de lo posible, su propio desarrollo económico, social y cultural. Además, dichos pueblos deberán participar en la formulación, aplicación y evaluación de los planes y programas de desarrollo nacional y regional susceptibles de afectarles directamente". 
artículo 16, letra a), de la Ley No 19.175, Orgánica Constitucional sobre Gobierno y Administración Regional, pues establece la obligación de participar a los pueblos indígenas en una función propia del gobierno regional que en el artículo 16, letra a), de la señalada ley se la entrega a dicho gobierno, sin limitaciones".

Definidas ambas normas como autoejecutables, a continuación en la Sentencia rol 1050-08 (a propósito del control de constitucionalidad del Convenio 169 por contener normas propias de una ley orgánica constitucional) el TC consideró que estaba en presencia de normas asimilables a leyes orgánico-constitucionales.

\section{El Concepto “autoejecutable" se vacía de Contenido en la SENTENCIA SOBRE Ley De PesCA}

$\mathrm{Al}$ momento de verificar el cumplimiento de la consulta a los pueblos indígenas el TC retrocede en los criterios antes acordados. En efecto, el Tribunal considera que lo que había definido como autoejecutabilidad, era en verdad una exhortación al legislador a dar desarrollo normativo a los compromisos asumidos en el tratado internacional. Que mientras dicho desarrollo no se produjera, el TC no está habilitado para pronunciarse sobre el cumplimiento del trámite de consulta.

"Vigésimo tercero: Que, consecuentemente, la auto-ejecutividad de un tratado internacional no obsta al desarrollo legislativo del mismo sino que, por el contrario, lo impele. Es el legislador quien debe definir las autoridades u organismos representativos de las etnias originarias con derecho a participar en la consulta; la oportunidad y forma de participación en los procesos legislativos pertinentes, de modo libre, informado y no coaccionado, además de fijar el procedimiento. Sólo en esas condiciones este Tribunal Constitucional estará en situación de controlar si, efectivamente, se han creado condiciones de participación igualitarias para los pueblos indígenas...".

El carácter autoejecutable no supone que las normas ingresen directamente al ordenamiento interno. Lo que ocurriría en el caso de normas autoejecutables, según criterio del TC, es que surgiría, una vez ratificado el tratado, la obligación para el legislador de dar desarrollo normativo, pero mientras dicho desarrollo no se produzca, las normas del tratado no serían de directa aplicación. Dicho en otras palabras, sólo una vez que el desarrollo normativo en el derecho interno se produzca es que el TC se pronunciaría sobre su constitucionalidad no siendo suficiente con la ratificación del tratado para el surgimiento de las obligaciones internacionales que la norma contiene". 
Recordemos nuevamente lo que se dijo en la sentencia Rol No 309: "Las primeras [normas autoejecutables], son las que tienen el contenido y precisión necesarias que las habilita para ser aplicadas sin otro trámite como fuente del derecho interno. En otros términos, son auto suficientes, y entran a la legislación nacional cuando el tratado que las contiene se incorpora al derecho vigente".

Como hemos visto, el TC señaló antes que una norma autoejecutable se distinguía de una no autoejecutable en el hecho que estas últimas "requieren para su entrada en vigencia de la dictación de leyes, reglamentos o decretos que las implementen y, en tal evento, las haga aplicables como fuente del derecho interno".

No encontramos coherencia entre una doctrina y la otra. El Tribunal definió la autoejecutabilidad de una norma como su poder de ingresar al ordenamiento sin norma habilitante. Si la interpretación sostenida en la sentencia sobre ley de pesca hubiera quedado claramente establecida, el legislador habría sido exhortado hace 4 años para dictar las normas complementarias. Los poderes del Estado, el Ejecutivo y el Legislador, han operado en la lógica de la eficacia de la consulta en las hipótesis analizadas. Si ésta hubiera sido la doctrina inicial, ya los poderes del Estado debieron de haber actuado para el desarrollo normativo de la consulta.

\section{LA SENTENCIA SUPONE UNA RUPTURA CON LA ANTERIOR DOCTRINA DEL TC}

Siguiendo con la primera doctrina del tribunal, la norma autoejecutable no requiere desarrollo normativo una vez ratificado el tratado, por ello, uno de los argumentos del Ejecutivo a la hora de responder al requerimiento es que no existen materias que afecten a los pueblos indígenas en la ley de pesca, y que por esta razón no se consultó. Por el contrario, el Ejecutivo destaca los avances en esta materia y hace alusión al D.S. No 124 como la norma que ha regulado las consultas que se han hecho hasta ahora, y para dar cumplimiento al convenio y a la doctrina del mismo Tribunal en relación a normas autoejecutables:

"Desde el año 2009 se han realizado más de 23 consultas al amparo del artículo $6^{\circ}$ del Convenio 169 de la OIT, aludiendo en concreto a ocho de ellas. Además, en cumplimiento de las recomendaciones del relator James Anaya, se ha implementado un proceso de consulta acerca de la consulta, en desarrollo desde marzo de 2011, y que incluye al Congreso Nacional...

Sostiene que en el fallo Rol No 1050 se señaló que el Convenio se refiere a materias de ley orgánica constitucional en lo relativo a la participación a nivel local, regional y nacional, que la consulta altera procedimientos administrativos, que en materia 
legislativa pasa a ser obligatoria de realizar, que la participación consultiva no puede adoptar formas plebiscitarias y que su resultado no es vinculante al no poder afectar atribuciones privativas de fuente constitucional...

En conclusión, el Convenio 169 de la OIT sólo puede modificar normas de leyes orgánicas constitucionales, mas no la propia Constitución.

Alude además al fallo Rol No 1988, recaído en el Convenio UPOV 91, en el cual se señaló que corresponde al Gobierno, al Congreso Nacional, a los Municipios y demás órganos autónomos determinar los mecanismos necesarios y apropiados para la consulta, ratificando que no es un asunto de constitucionalidad. En el mismo fallo se señaló expresamente en votos particulares que la no concurrencia de la consulta no era un vicio de constitucionalidad...

A continuación destaca que el deber de consulta ha sido usado por la Corte Suprema como parámetro del juicio de legalidad propio de la acción de protección, atribuyéndole así rango de norma legal, detallando cinco casos de protecciones ambientales y agregando dictámenes de la Contraloría General de la República, que lo utiliza como elemento del examen de legalidad...

El convenio no establece qué es "afectación directa”, quedando ello sujeto al margen de apreciación de la realidad local, a la luz de las ideas matrices del proyecto y de los reglamentos del Ejecutivo, en concordancia con los criterios de la OIT, siempre que se pretenda dar ejecución a normas del convenio o la medida produzca afectación directa. Así, no todas las leyes deben consultarse ni cualquier afectación da lugar a consulta, por lo que este proyecto de ley no la requiere...

Expone que el único estándar de afectación directa vigente es el del D.S. No 124/2009 de MIDEPLAN, que exige relación exclusiva con tierras indígenas o áreas de desarrollo establecidas en la Ley No 19.253, o que se refiera a una mayoría significativa de comunidades, asociaciones y organizaciones indígenas determinadas o determinables, a lo que la Corte Suprema ha agregado el elemento de proporcionalidad en el análisis de la materia”.

De esta forma, para el Ejecutivo no se trata del incumplimiento del deber de consulta, se trata de que no corresponde dicho trámite por no verse afectados derechos de los pueblos indígenas.

\section{LA TARDÍA EXHORTACIÓN AL LEGISLADOR}

No sólo el actual Ejecutivo consideró que el Estado estaba dando cumplimiento al Convenio ratificado por el país, así también lo consideró el Ejecutivo presidido por la ex presidenta Michelle Bachelet, cuando señala en los considerandos del D.S. No 124: 
“7) Que en virtud de lo dispuesto en el artículo 38 No 3 del Convenio No 169, éste entrará en vigor para el Estado de Chile doce meses después del registro de su ratificación; es decir, el 15 de septiembre de 2009;

8) Que una vez que el Convenio entre en vigencia, los artículos $6^{\circ} N^{\circ} 1$ letra a) y $N^{\circ} 2$, y $7^{\circ} N^{\circ} 1$ oración segunda del Convenio $N^{\circ} 169$ pasarán a formar parte de la legislación vigente, ya que dichas normas tienen el contenido y precisión necesarias que las habilita para ser aplicadas sin otros trámites como fuente del derecho interno;

9) Que el Relator Especial de Naciones Unidas sobre la situación de los derechos humanos y las libertades fundamentales de los indígenas ha señalado que, en aquellos casos en que los mecanismos para llevar a cabo la consulta no existan formalmente, deberán adoptarse provisionalmente mecanismos transitorios con miras al ejercicio efectivo de ésta;

10) Que se dará inicio a un proceso de consulta a los pueblos indígenas, a nivel nacional, acerca del procedimiento para llevar a cabo los procesos de consulta, de acuerdo a los artículos $6^{\circ} \mathrm{N}^{\circ} 1^{\circ}$ letra a) y No $2^{\circ}$, y $7^{\circ}$ No $^{\circ}$ oración segunda del Convenio No 169 ;

11) Que, atendido lo anterior, se hace necesario adoptar un mecanismo que regule la consulta y la participación de los pueblos indígenas interesados, estableciendo procedimientos claros, transparentes y sistemáticos, a fin de lograr una adecuada implementación de las respectivas normas del Convenio".

Luego de casi 4 años desde la vigencia del Convenio 169 no existe regulación del derecho a la consulta, por tanto, mientras ese desarrollo no se produzca el Congreso podrá definir primero si consulta y segundo las modalidades y alcances de dicho trámite. Por otra parte, llama la atención que el Tribunal no hiciera referencia al D.S. No 124. Este era el mecanismo previsto (se ha aplicado hasta ahora), si ya no lo es, entonces estamos ante una materia de ley y sólo el legislador puede definir su regulación.

Este es otro de los problemas que plantea la sentencia, el Tribunal dice y es correcto, que el legislador no se ha pronunciado en esta materia, pero sí lo había hecho el Ejecutivo para proveer un instrumento que provisionalmente regulara el derecho a la consulta. Habría sido valioso que el Tribunal Constitucional explicara la razón para considerar que estaba ante una omisión del legislador que no podía ser colmado por el Ejecutivo, deberíamos concluir que estamos ante una materia propia del dominio legal.

Conforme al art. 27 de la Convención de Viena sobre Derecho de los Tratados, Chile no puede aludir a razones de orden interno para dejar de cumplir con las obligaciones asumidas. Mientras el legislador no del desarrollo normativo al tratado, el derecho a la consulta se resolverá caso a caso. 
Nos parece, en definitiva, que el Tribunal estuvo frente a una oportunidad para seguir desarrollando su doctrina y concretar lo que antes afirmó en relación a las normas autoejecutables. Dicha continuidad era la que, opinamos, podía esperarse de su doctrina. Con esta sentencia se vacía de contenido a la definición del carácter autoejecutable de una norma. Un cambio en sus criterios, que creemos es lo que ha ocurrido en este caso, habría merecido un desarrollo argumentativo distinto al que aquí se ha planteado.

No cabe duda que el derecho a la consulta seguirá siendo motivo de controversias y tensiones, ahora al problema se instalará en el Congreso que deberá acordar en definitiva cómo y en qué casos debe consultarse a los pueblos indígenas. Según ha quedado resuelto en esta sentencia, mientras este desarrollo no ocurra, el derecho a la consulta será definido por el Congreso en cada caso. No parece ser ésta una solución acorde con los compromisos asumidos por el Estado cuando ratificó el Convenio 169. Luego de esta sentencia, sigue el Derecho Internacional de los Derechos Humanos sometido a vaivenes, marchas y contramarchas. 